\title{
PERANCANGAN SISTEM OTOMASI PROSES PELUBANGAN KARTU TEKSTIL JACQUARD PADA MESIN PUNCHING DI PT. BUANA INTAN GEMILANG
}

\section{AUTOMATION SYSTEM DESIGN PUNCHING PROCESS FOR JACQUARD TEXTILE CARD ON PUNCHING MACHINE AT PT. BUANA INTAN GEMILANG}

\author{
${ }^{1}$ Luqman Abdul Hakim, ${ }^{2}$ Rino Andias Anugraha \\ ${ }^{1,2}$ Program Studi Teknik Industri, Fakultas Rekayasa Industri, Telkom University \\ 12abdulmanhakim.tlc@gmail.com, 2rinoandias@telkomuniversity.ac.id
}

\begin{abstract}
Abstrak- Seiring perkembangan teknologi yang sangat pesat, mendorong industri tekstil untuk dapat menerapkan teknologi kedalam proses produksinya, salah satu teknologi tersebut yaitu otomasi. Penggunaan sistem otomasi di sebuah industri manufaktur dapat meningkatkan produktivitas. PT Buana Intan Gemilang adalah salah satu industri tekstil yang memproduksi komoditas kain greige, sajadah, dan gorden dengan beragam jenis corak. Permintaan corak yang selalu meningkat sehingga perusahaan harus meningkatkan produktivitas mesin, operator, dan sistem dalam memproduksi kartu corak yang dinamakan kartu jacquard yang jumlahnya ribuan. Permasalahan yang muncul yaitu proses produksi yang masih semi-otomatis, dimana keterlibatan aktvitias operator yang berulang, waktu siklus yang tidak konsisten sehingga terjadi ketidakmampuan perusahaan dalam memenuhi target produksi. Perancangan sistem otomasi pada mesin punching menggunakan Programmable Logic Controller (PLC) sebagai pengendali utama dalam proses dengan bantuan metode User Requirement Spesification (URS) untuk menentukan solusi terhadap perencanaan sistem otomatisasi yang didesain agar dapat diterapkan dalam pemecahan masalah. Dari penelitian yang dilakukan dapat disimpulkan bahwa, perancangan sistem otomatisasi untuk kartu jacquard pada mesin punching pada PT Buana Intan Gemilang telah selesai dilakukan dan mengurangi waktu siklus yaitu sekitar 10 detik/kartu. Dengan menggunakan sistem otomasi pada proses produksi kartu jacquard ini diharapkan dapat meningkatkan kapasitas produksi dan dapat mengurangi beban tenaga kerja sehingga memberikan keuntungan dan produktivitas perusahaan.
\end{abstract}

Kata kunci: Otomasi, Produktivitas, Kartu Tekstil Jacquard, Programmable Logic Controller, User Requirement Spesification, Waktu Siklus.

\footnotetext{
Abstract-As the rapid development of technology, its encouraging textile industry to be able to implement it into the production process, its automation system regarding can improve the productivity. PT. Buana Intan Gemilang is one of textile industry which manufactures greige, sajadah, and curtains fabric within various pattern. Increasing demand regarding pattern therefore company should intensify productivity of machine, operator, and system in order to produce pattern card called jacquard card in thousand amounts. The problem statement which showed is the manufacturing process is still manual rely on recur the operator's activities, inconsistent cycle time that occurs on incapacity production target. Automation system design on punching
}

machine using a Programmable Logic Controller (PLC) as the primary controller with using User Requirement Spesification (URS) for providing the solution in designing automated system implemented to solve the problem. According to conducted research it can be conclude that, automation system design for jacquard on punching machine at PT. Buana Intan Gemilang has been accomplished and decrease the cycle time around 10 seconds/card. By using automation system on jacquard card production is expected to increase the production capacity and eliminate the workload of operator therefore offer benefit and productivity of company.

Keywords: Automation, Productivity, Jacquard Textile Card, Programmable Logic Controller, User Requirement Spesification, Cycle Time.

\section{PENDAHULUAN}

PT Buana Intan Gemilang (PT BIG) adalah salah satu perusahaan lokal dibidang Tekstil dan Produk Tekstil (TPT) yang memproduksi tiga komoditas kain diantaranya; kain greige, kain sajadah, dan kain gorden. Untuk mendukung produksi komoditas tersebut, perusahaan juga memproduksi alat bantu yang digunakan dalam pembuatan corak komoditi dengan kartu pola tekstil atau kartu jacquard. Kartu jacquard adalah sebuah kartu yang berlubang dengan pola yang sudah ditentukan sebelumnya untuk mekanisme pengaturan benang lusi secara teratur dan disesuaikan dengan lubang-lubang pada kartu [1]. Merupakan alat bantu dalam pembuatan corak dan salah satu bagian dari proses penenunan sebagai pembuatan pola pada kain greige (mentah). Kemudian kartu ini diduplikasi untuk memperbanyak corak yang dibuat sesuai permintaan konsumen. Konsumen dari perusahaan PT BIG adalah konsumen yang tidak secara langsung menggunakan produk akhir, melainkan perusahaanperusahaan lain yang mengolah kembali produk tekstil tersebut sebelum dijual ke tangan konsumen akhir. Berdasarkan Gambar 1, permintaan corak kain di PT BIG untuk setiap bulannya mengalami trend positif dimulai dari bulan Mei. Dalam satu tahun, permintaan corak dapat dipesan hinga 90 corak baru dan berbeda. Permintaan jumlah corak terbanyak terjadi di bulan November. Peningkatan permintaaan terbesar pada bulan Juni sebesar 33\% terhadap 
bulan Mei dan pada selanjutnya mengalami kenaikan rata-rata permintaan corak sebesar $11 \%$.

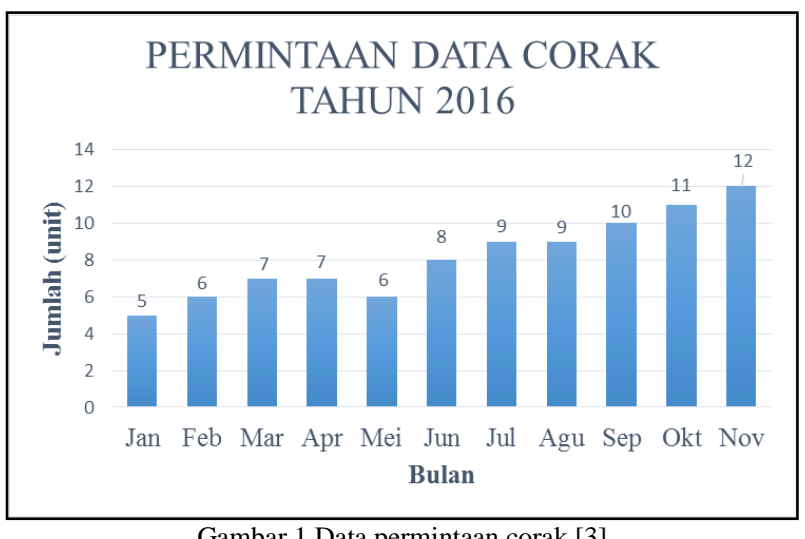

Gambar 1 Data permintaan corak [3]

Ditinjau dari permintaan bulan Mei hingga November yang mengalami peningkatan, dibutuhkan kinerja dan produktivitas dari operator dan mesin produksi. Corak yang diproduksi dengan sebuah kartu yang disebut dengan kartu jacquard ini ditemukan oleh seorang ilmuwan berkebangsaan Inggris, Joseph Marie Jacquard (17521834). Berdasarkan Tabel I dijelaskan bahwa data parameter proses pelubangan kartu jacquard masih menggunakan sistem konvensional. Dimana aktivitas pekerja pada stasiun kerja pelubangan kartu masih sangat bergantung dan melakukan aktivitas yang berulang. Dimulai dari pekerja mengambil raw material kartu, menekan tuas penjepit kartu, melakukan setup pada mesin dan komputer, menekan tuas slider-block, dan mengambil kartu yang telah selesai. Dengan melihat kondisi tersebut hasil data observasi penelitian menghasilkan banyak ketidakefektifan pada proses produksi kartu jacquard. Pekerja mengulang aktivitasnya selama proses pelubangan kartu jacquard telah selesai. Pada kondisi normal, mesin dapat memproduksi kartu sebanyak 300 kartu/hari, dengan kondisi saat ini tujuh jam kerja yang kemudian tidak dapat memenuhi kapasitas target produksi.

TABEL I

OBSERVASIDATA KONDISISAATINI

\begin{tabular}{|c|c|}
\hline Parameter & Angka \\
\hline Waktu Siklus & 95-96 detik/unit \\
\hline Jam Kerja & 7 jam/hari \\
\hline Kapasitas Target & 300 unit/shift \\
\hline Tenaga Kerja & 1 pekerja/shift \\
\hline
\end{tabular}

Ditinjau dari permasalahan diatas dibutuhkan kinerja dan modifikasi sistem dari mesin produksi tersebut. Untuk itu penerapan sistem otomasi pada keseluruhan mesin punching ini sangat diperlukan. Teknologi otomasi merupakan sebuah teknologi yang proses maupun prosedurnya diselesaikan tanpa keterlibatan langsung manusia juga mengurangi pekerjaan yang berulang-ulang. Penerapan teknologi otomasi digunakan dalam dunia industri agar dapat meningkatkan akurasi, presisi, dan produktivitas dari suatu proses industri, yang ditandai dengan meningkatnya jumlah dan kualitas keluaran yang dihasilkan [8]. Dari permasalahan diatas, perbaikan dapat dilakukan dengan memodifikasi sistem otomasi pada mesin punching sehingga operator tidak melakukan proses yang berulangulang dalam pengambilan kartu sebelum dan sesudah proses punching. Alasan penggunaan sistem otomasi secara keseluruhan untuk mencapai tingkat kapasitas produksi optimal dan pengurangan waktu siklus produksi. Pengaplikasian sistem otomasi pada mesin produksi akan menghasilkan keuntungan untuk perusahaan seperti, pengurangan waktu siklus, peningkatan kualitas produk, dan pengurangan beban operator. Pengembangan sistem otomasi dapat diharapkan mengurangi beban operator dalam melakukan aktivitas dan berjalan otomatis tanpa campur tangan manusia. Metode penelitian ini digunakan untuk meningkatkan kapasitas produksi kartu jacquard dan dapat mengurangi waktu siklus proses produksi dengan merancang dan mengembangkan sistem otomasi mesin punching pada aspek mekanika dan elektronika.

\section{STUDILITERATUR}

\section{A. Kartu Jacquard}

Merupakan alat bantu dalam pembuatan corak dan salah satu bagian dari proses penenunan sebagai pembuatan pola pada kain greige (mentah). Ide kartu ini ditemukan oleh seorang ilmuwan berkebangsaan Inggris, Joseph Marie Jacquard (1752-1834). Kartu jacquard dapat mengontrol kerja masing-masing benang lusi secara bebas [2]. Prinsipnya sederhana namun terbukti sangat efektif. Menurut [1], bagian kartu yang berlubang, melalui suatu mekanisme tertentu kemudian menghasilkan gerakan mengangkat benang lusi yang terhubung dengan lubang tersebut. Sebaliknya, bagian yang tidak berlubang adalah kode perintah mekanik untuk tidak mengangkat benang lusi sesuai Gambar 2.

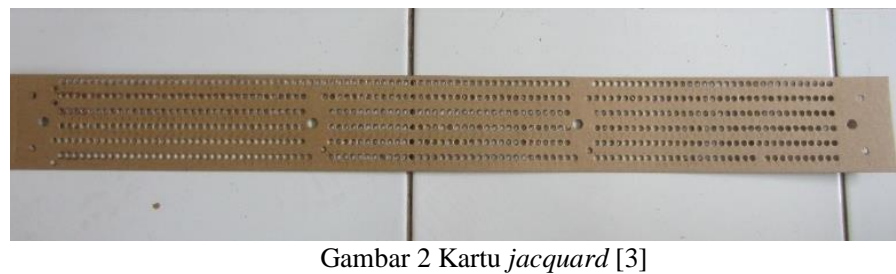

\section{B. Sistem Otomasi}

Otomasi adalah teknologi yang dapat melakukan serangkaian proses secara otomatis tanpa adanya bantuan manusia. Hal ini diimplementasikan dengan menggunakan program instruksi dikombinasikan dengan sistem kontrol. Dalam otomatisasi, daya dibutuhkan untuk mendorong proses dan untuk mengoperasikan program dan sistem kontrol [4]. Secara umum, sistem otomasi dapat didefinisikan sebagai integrasi dari mekanika, sistem kelistrikan, dan sistem komputer yang dapat menggantikan peran manusia dalam suatu proses. Otomasi dapat bekerja untuk kegiatan yang berulangulang dan aktivitas yang tidak dapat dilakukan oleh manusia [6]. Penerapan teknologi otomasi digunakan dalam dunia industri agar dapat meningkatkan akurasi, presisi, dan produktivitas dari suatu proses industri, yang ditandai dengan meningkatnya jumlah dan kualitas keluaran yang dihasilkan [8]. Sehingga ada beberapa pendektaan yang digunakan dalam penerapan sistem otomasi, salah satunya adalah pendekatan The USA Principle: 
1. Understand the Existing Process

Pada tahap ini, proses eksisting harus dipahami dengan baik dan detail. Dimulai dari input, proses, output yang terjadi di antara input dan output, serta fungsi dari setiap proses.

2. Simplify the Process

Setelah proses keadaan awal dipahami dengan baik, langkah selanjutnya adalah menyederhanakan proses. Proses pada keadaan awal dikaji lebih lanjut, apakah dapat dihilangkan atau digabungkan tanpa menghilangkan fungsi dari proses itu sendiri.

3. Automate the Process

Langkah terakhir adalah penerapan otomasi pada proses tersebut.

\section{IEC 6613-3 Standard of PLC Programming}

Bahasa baku yang digunakan untuk melakukan pemrograman otomasi menggunakan PLC (Programmable Logic Controller) mengacu pada standar IEC 6613-3. IEC (International Electrotechnical Commision) adalah suatu organisasi yang mengeluarkan peraturan standar pada konsep elektrikal, ukuran, dan SOP peralatan elektronik termasuk PLC. Terdapat lima bahasa pemrograman standar diantaranya; Ladder Diagram (LD), Function Block Diagram (FBD), Instruction List (IL), Structured Text (ST). Ladder Diagram merupakan pemrograman yang sering digunakan di skala sistem kontrol industri. Salah satu keuntungan menggunakan Ladder Diagram yaitu bahasa program mudah dipahami dan dianalisis.

\section{Sequential Functional Chart (SFC)}

Sequential Functional Chart (SFC) secara grafis fokus menampilkan fungsi sekuensial sistem otomatis sebagai serangkaian langkah atau step dan transisi dari satu keadaan sistem ke sistem selanjutnya [9]. Transisi akan selalu berubah dari satu langkah ke langkah selanjutnya. Diagram ini menjelaskan sebuah closed-loop pada proses yang memiliki umpan balik jika terdapat kesalahan proses. Gambar 3 menunjukkan contoh diagram SFC.

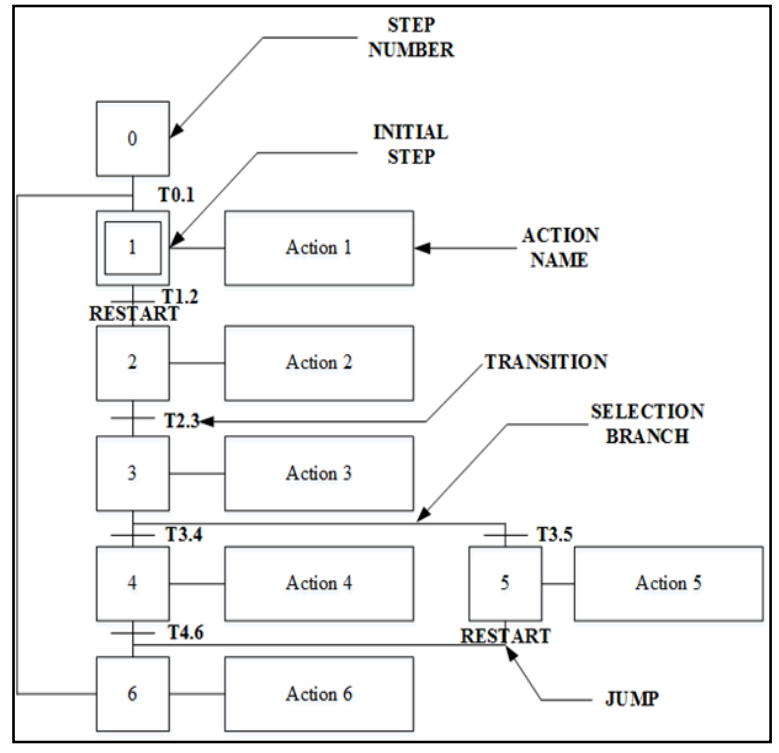

Gambar 3 Diagram SFC

\section{METODOLOGI PENELITIAN}

Penelitian dilakukan berdasarkan metode konseptual dari pengembangan model mesin kondisi saat ini dan kebutuhan spesifikasi untuk dapat merancang sistem otomasi pada objek mesin dan dilakukan simulasi hasil rancangan sistem. Studi utama pada penelitian yaitu bagaimana merancangan sistem otomasi pada mesin punching kartu jacquard untuk mengurangi waktu siklus produksi. Langkah pertama dimulai dari mengidentifikasi data dan proses kondisi saat ini pada mesin punching yang masih beroperasi secara konvensional yang belum dapat memenuhi target produksi sebanyak $300 \mathrm{kartu} / \mathrm{hari}$ dan waktu siklus selama 95 detik/kartu. Perancangan model mesin dan sistem otomasi ini menggunakan sistem kontrol PLC Omron CP1E dan disimulasikan melalui software monitoring HMI (Human Machine Interface) setelah model mesin dan program telah diimplementasikan. Sistematika User Requirement Specification (URS) berperan dalam membuat perancangan kebutuhan komponen dan deskripsi proses pada sistem otomasi secara keseluruhan [5] sehingga didapatkan komponen yang sesuai dan feedback dari deskripsi proses sistem otomasi. Metode konseptual dari penelitian dijelaskan pada Gambar 4.

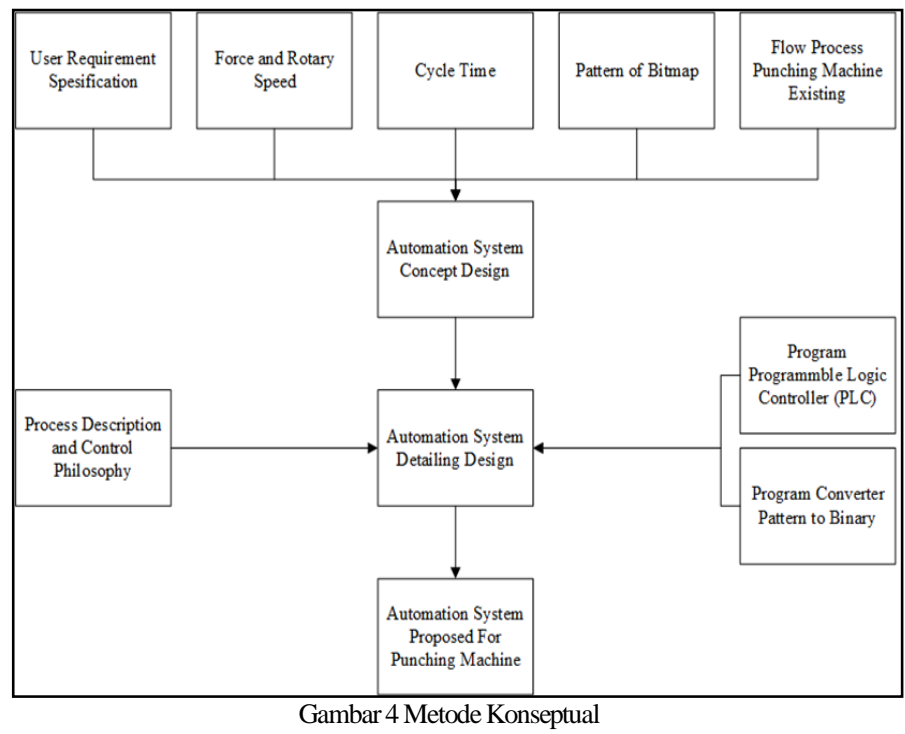

\section{HASIL DAN ANALISIS}

A. Identifikasi Komponen Sistem

Dalam merancang kebutuhan sistem otomasi, terdapat identifikasi kebutuhan perangkat lunak dan perangkat keras untuk menunjang sistem berjalan dengan lancar. User Requirement Spesification (URS) dapat digunakan untuk dapat menjelaskan dan menganalisis instrumentasi yang kemudian dirancang [7] seperti pada Tabel II.

Adapun perangkat lunak yang digunakan untuk menunjang keberhasilan aktuator dari sebuah perangkat keras. Terdapat lima penjelasan perangkat lunak yang dilakukan konfigurasi: 
TABEL II

KEBUTUHAN SISTEMPERANGKAT KERAS

\begin{tabular}{|r|c|c|}
\multicolumn{1}{|c|}{ No Nama Komponen } & Kuantitas \\
\hline 1 & Programmable Logic Controller Omron CPIE & 2 \\
\hline 2 & Auto-feeder & 1 \\
\hline 3 & Inverter & 1 \\
\hline 4 & Motor AC & 2 \\
\hline 5 & Capacitive Proximity Sensor & 2 \\
\hline 6 & Limit Switch Sensor & 4 \\
\hline 7 & Emergency Button & 1 \\
\hline 8 & Button & 13 \\
\hline 9 & Indicator & 14 \\
\hline 10 & Solenoid & 13 \\
\hline
\end{tabular}

1. Sistem Operasi Windows XP SP3

Sistem operasi utama yang digunakan untuk mengeksekusi program dari PLC, HMI, dan Excel Converter yaitu menggunakan sistem operasi Windows XP SP 3 karena dapat bekerja dengan maksimal dan mendukung dari perangkat lunak lainnya.

\section{CX-Programmer 9.4}

Merupakan salah satu perangkat lunak yang digunaan untuk memprogram bahasa ladder diagram pada PLC seri Omron. Memiliki banyak fungsi yang terintegrasi dengan perangkat keras PLC dan cocok digunakan di skala industri. Beberapa fungsi pada perangkat lunak ini dapat mengkonfigurasi dengan mudah apabila perangkat keras yang digunakan berbeda tipe PLC dan mudah memahami program bahasa ladder diagram.

3. Microsoft Excel 2007 with Image Converter Adds-in Memiliki fungsi untuk mengkonversi gambar menjadi deretan angka biner yang disisipi pada perangkat lunak Microsoft Excel 2007. Hasil angka biner kemudian diintegrasikan pada monitoring dan menjadi data masukan PLC.

\section{Wonderware Intouch}

Salah satu perangkat lunak yang berfungsi untuk melakukan proses monitoring dan memvisualisasikan data pada sistem kontrol. Perangkat antarmuka ini menghubungkan mesin dengan operator dengan presisi, akurat, dan real-time.

\section{Solidworks Dassault System 2015 Edition}

Merupakan salah satu perangkat lunak CAD (Computer Aided Design) untuk membuat komponen, sketsa, atau model mesin.

\section{E. Rancangan Konfigurasi Sistem Program PLC}

Ksifn jdhf gk perancangan Perancangan dilakukan dengan mengindentifikasi kebutuhan instrumentasi yang diperlukan seperti sensor, aktuator, dan sistem kontrol yang cocok digunakan pada sebuah objek yang di otomatisasikan. CX-Programmer adalah perangkat lunak yang digunakan untuk membuat rancangan program ladder diagram (LD) pada PLC dengan menggunnfaj fhdfkan tipe PLC Omron CP1E yang telah memiliki standar dari IEC 6113-3. Program ini dapat dilakukan untuk menginisialisasi sistem program, monitoring, dan debugging. Software yang sesuai dengan kebutuhan perangkat keras PLC CP1E. Dapat dilihat pada Gambar 4 merupakan hierarki dari software untuk melakukan rancangan program pada mesin punching.

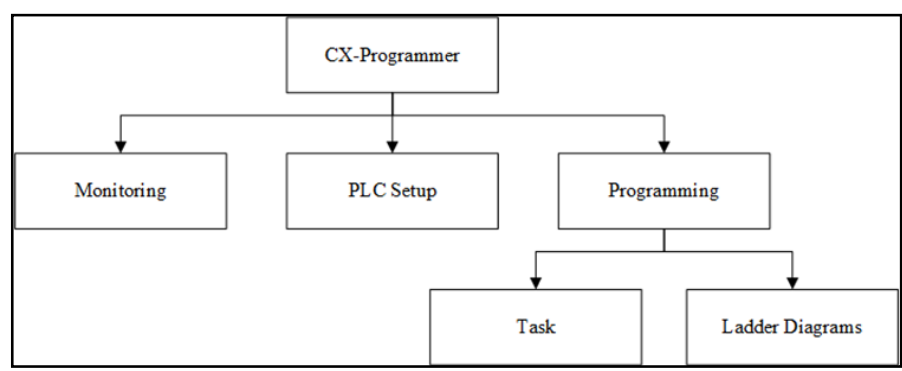

Gambar 4 Hierarki Program PLC

Terdapat tiga bagian dari hierarki CX-Programmer diantaranya; monitoring, merupakan salah satu fungsi untuk memeriksa visualisasi ladder diagram sebagai identifikasi input dan output yang telah diberikan, PLC Setup merupakan fungsi dalam mengkonfigurasi model hardware dan protokol komunikasi antara komputer dengan PLC, Programming merupakan fungsi utama dimana user membuat ladder diagram untuk mengeksekusi proses. Untuk mendukung pemahaman pada program PLC pentingnya untuk membuat rancangan input dan output pada sistem sebagai jembatan penghubung user dengan sistem kontrol yang dibutuhkan untuk mesin punching. Input dan output dirancang untuk dapat terintegrasi dengan sistem kontrol pada PLC. Pengalamatan perlu disesuaikan dengan benar dan terurut agar pengeksekusian program berjalan lancar. Tujuannya untuk menerima sinyal atau sumber tenaga listrik sehingga dapat mengirimkan sinyal pada output atau aktuator. Untuk itu perlu memudahkanUntuk itu perlu memberikan alamat pada sistem input dan output sehingga dapat memudahkan dalam proses troubleshooting dan maintenance. Pada Tabel III dan IV dijelaskan deskripsi kebutuhan untuk sistem input dan output pada PLC Omron CP1E.

TABEL III

ALAMAT INPUTPADA PLC

\begin{tabular}{|r|c|c|c|c|} 
No. Nama & \multicolumn{1}{c}{ Tipe Saklar } & Tipe Data & Alamat \\
\hline 1 & Emergency_Button & Detent Button & BOOL & 0.00 \\
\hline 2 & Reset_Button & Push Button & BOOL & 0.01 \\
\hline 3 & Power_System_Button & Detent Button & BOOL & 0.02 \\
\hline 4 & Auto_Selector & Selector 3 Position & BOOL & 0.03 \\
\hline 5 & Man_Selector & Selector 3 Position & BOOL & 0.04 \\
\hline 6 & Feeder_Button & Push Button & BOOL & 0.05 \\
\hline 7 & Lever_Release-Hold_Button & Detent Button & BOOL & 0.06 \\
\hline 8 & Push_Card_Button & Push Button & BOOL & 0.07 \\
\hline 9 & Auto_Run_Button & Push Button & BOOL & 0.08 \\
\hline 10 & One_Cycle_Button & Push Button & BOOL & 0.09 \\
\hline 11 & Slider_Reverse_Button & Push Button & BOOL & 0.10 \\
\hline 12 & Slider_Forward_Button & Push Button & BOOL & 0.11 \\
\hline 13 & Reverse_Feeder_Button & Push Button & BOOL & 1.00 \\
\hline 14 & Forward_Feeder_Button & Push Button & BOOL & 1.01 \\
\hline 15 & Sensor_Detect_Slider1 & Trigger & BOOL & 1.02 \\
\hline 16 & Sensor_Detect_Card_Down & Trigger & BOOL & 1.03 \\
\hline 17 & Sensor_Detect_Card_Up & Trigger & BOOL & 1.04 \\
\hline 18 & Sensor_Detect_Slider2 & Trigger & BOOL & 1.05 \\
\hline
\end{tabular}


TABEL IV

ALAMAT OUTPUTPADA PLC

\begin{tabular}{r|l|c|c|c|}
\multicolumn{2}{c}{ No. Nama } & Tipe Output & Tipe Data & Alamat \\
\hline 1 & Auto_Indicator & Lamp & BOOL & 100.00 \\
\hline 2 & Man_Indicator & Lamp & BOOL & 100.01 \\
\hline 3 & Motor_Feeder & Motor & BOOL & 100.02 \\
\hline 4 & Additional_Output & Lamp & BOOL & 100.03 \\
\hline 5 & Red_Indicator & Lamp & BOOL & 100.04 \\
\hline 6 & Yellow_Indicator & Lamp & BOOL & 100.05 \\
\hline 7 & Green_Indicator & Lamp & BOOL & 100.06 \\
\hline 8 & Sol_Push_Card & Solenoid & BOOL & 100.07 \\
\hline 9 & Sol_Release-Hold & Solenoid & BOOL & 101.00 \\
\hline 10 & Sol_Scissors & Solenoid & BOOL & 101.01 \\
\hline 11 & Motor_Slider_Forward & Motor & BOOL & 101.02 \\
\hline 12 & Motor_Slider_Reverse & Motor & BOOL & 101.03 \\
\hline
\end{tabular}

\section{F. Rancangan Konfigurasi Panel Box}

Salah satu tujuan perancangan panel box adalah untuk menciptakan pemahaman yang jelas bagi operator yang mengendalikan proses, mencangkup keamanan dan dapat dilakukannya perawatan berkala. Panel box dirancang dengan pertimbangan spesifikasi kebutuhan pengguna yang mempertimbangkan ukuran mesin. Selain itu untuk memasang komponen listrik atau komponen elektronik industri seperti PLC, relay, sumber tenaga, contactor, dan lain-lain.

\section{G. Rancangan Program HMI}

Human Machine Interface (HMI) merupakan salah satu tools dari sistem otomasi yang berfungsi untuk menampilkan data informasai secara visual dan mendukung sistem kontrol untuk memudahkan dalam mengumpulkan dan menganalisis data. Rancangan monitoring HMI menggunakan perangkat lunak Wonderware Intouch Ver. 10.1. HMI sangat penting untuk pengaplikasian sistem otomasi dalam komunikasi antara mesin dan operator. Terdapat dua antarmuka rancangan utama yang mendukung monitoring pada saat memproduksi kartu jacquard yaitu; antarmuka monitoring biner yang menjadi data informasi utama pada proses pelubangan kartu jacquard. Antarmuka ini menjadi sebuah platform untuk menyimpan hasil konversi biner dari perangkat lunak converter menjadi data masukan PLC untuk mengeksekusi program pelubangan kartu. Hasil rancangan antarmuka ini dijelaskan pada Gambar 5.

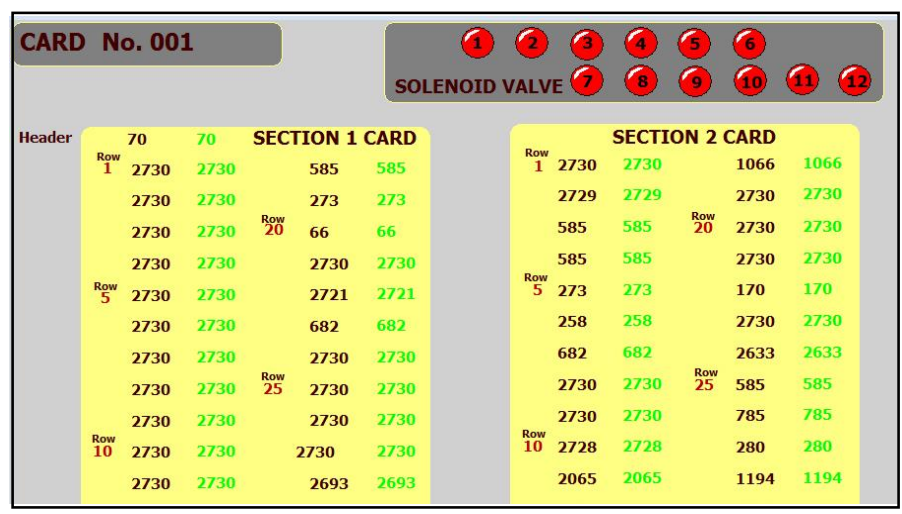

Gambar 5 Halaman antarmuka proses pelubangan

Antarmuka yang berikutnya adalah antarmuka mekanisme otomatis mesin punching. Menjelaskan keadaan sensor, aktuator, dan mekanisme yang tejadi ketika sistem otomasi diaktifkan. Keadaan itu ditandai dengan indikator lampu yang dirancang pada antarmuka untuk memudahkan pekerja menganalisis jika terjadi failure system atau troubleshooting. Hasil rancangan dapat dilihat pada Gambar 6.

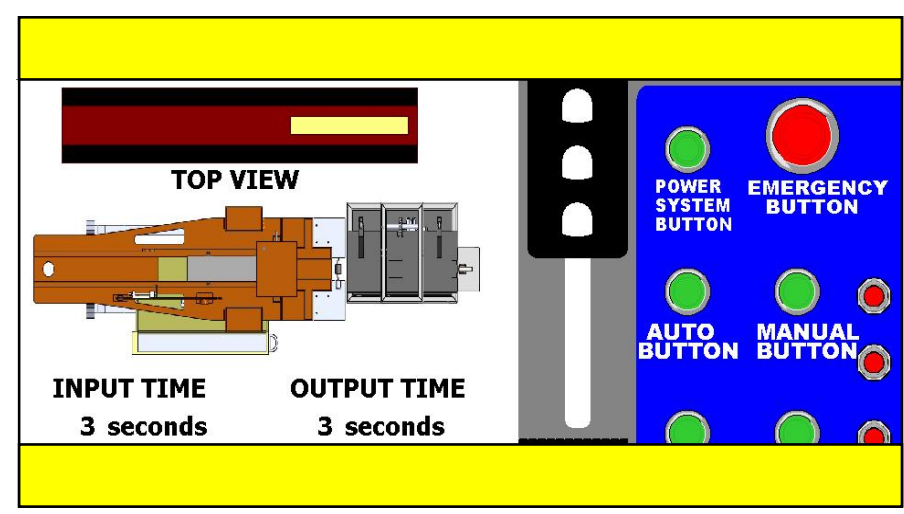

Gambar 6 Halaman antarmuka proses mekanisme mesin punching

Hasil yang telah dirancang perlu dianalisis untuk mengetahui apakah sistem yang telah diimplementasi dapat mengurangi waktu siklus dan meminimasi aktivitas operator yang berulang-ulang. Dimulai dari proses konversi gambar corak kemudian diolah dengan menggunakan software Image Converter to Binary yang telah menjadi adds-in pada Microsoft Excel 2007. Software ini merupakan macros dan visual basic programming dengan halaman antarmuka dibuat dengan salah satu tools pada Microsoft Excel yaitu VSTO (Visual Studio Tools for Office). Kartu jacquard memiliki variasi lubang yang dinterpretasikan dengan angka biner (1 dan 0). Angka ini didapatkan dari hasil konversi gambar corak yang dimasukkan pada perangkat lunak yang dapat dilihat pada Gambar 7.

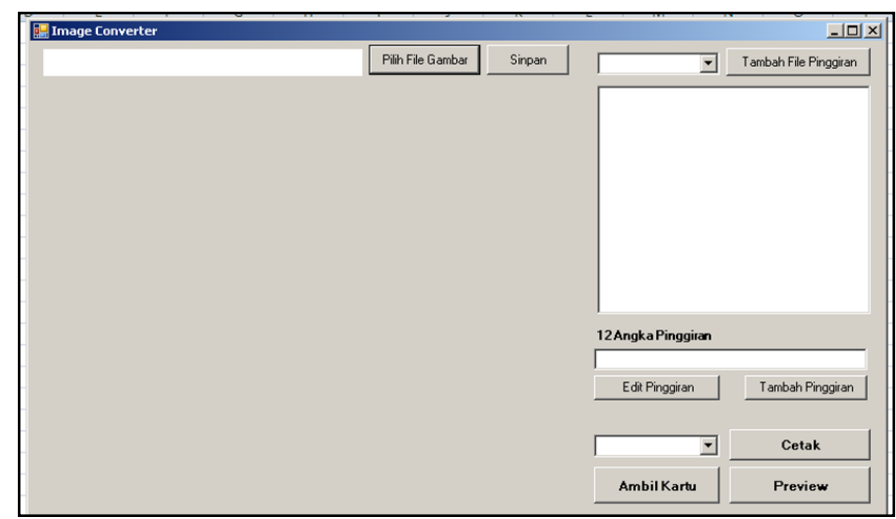

Gambar 7 Halaman antarmuka image converter to binary software

Setelah mengkonfigurasi program pada perangkat lunak, memasukkan gambar corak, dan menambahkan kode pinggiran. Program kemudia menjifhgkonversi hasil gambar menjadi deretan angka biner. Angka biner ini didapatkan dari gambar hitam putih untuk menghasilkan angka 1 dan 0 . Deretan ini memiliki sejumlah 101 baris biner yang disesuaikan dengan panjang kartu yang telah di proses. Baris pertama pada kartu jacquard dimulai pada kolom B hingga kolom N pada Microsoft Excel. Terdapat 12 angka biner yang merepresentasikan banyaknya jumlah solenoid untuk proses pelubangan kartu. Angka 1 menunjukkan aktifnya solenoid 
untuk pelubangan kartu sedangkan angka 0 tidak mengaktifkan solenoid. Angka biner yang dihasilkan menjelaskan apakah kartu kemudian dilubangi atau tidak dan dibagi menjadi tiga bagian. Bagian pertama kartu memiliki 35 baris vertikal dengan 12 baris horizontal. Bagian kedua dan ketiga kartu memiliki 33 baris vertikal dengan 12 baris horizontal. Sehingga total baris vertikal yang dimiliki kartu sebanyak 101 baris. Hasil konversi gambar menjadi angka biner dapat dilihat pada Gambar 8. Deretan ini juga menjumlahkan biner menjadi desimal yang dijadikan sebagai data masukan untuk pemrograman PLC.

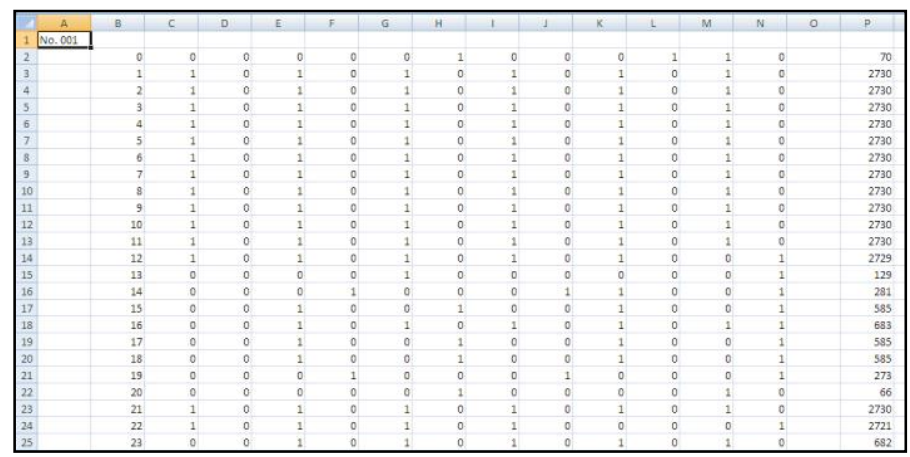

Gambar 8 Hasil konversi angka biner

Data angka desimal yang merupakan jumlah hasil deretan angka biner kemudia dikirimkan pada program pelubangan kartu jacquard dan dieksekusi oleh program mekanisme mesin punching.

\section{A. Analisis Urutan Proses}

Urutan proses Urutan proses diperlukan untuk menjelaskan setiap proses yang dilakukan secara rinci. Pada kondisi sistem saat ini, terdapat beberapa aktivitas yang menghabiskan waktu seperti menekan tuas penjepit, menekan tuas slider-block penjepit, dan menarik kabel katrol, dan lain-lain. Oleh karena itu, penelitian ini merancang perbaikan sistem desain model baru kedalam sistem otomatis untuk mendukung keseluruhan sistem. Berikut penjelasan analisis dalam uraian proses yang diusulkan adalah:

\section{Perbaikan Sistem Persiapan (Preparation System)}

Perancangan perbaikan preparation system pada desain mesin model baru yang diusulkan adalah untuk menunjukkan proses awal sampai proses selesai. Merancang tower lamp sebagai informasi pengecekan sistem.

\section{Perbaikan Sistem Auto-feeder}

Dalam kondisi saat ini, pekerja harus mengeluarkan kartu dari waddalam kondisi saat ini, pekerja harus mengeluarkan. ah kotak secara berulang ke dalam meja mesin kerja. Ini menyebabkan kelelahan pada operator dan proses waktu siklus yang tidak konsisten. Tujuan pembuatan model desain autofeeder adalah dengan menyimpan kartu yang sedang diproses. Perbaikan ini memastikan operator hanya memasukkan kartu dengan sekali atau batch sehingga pekerja hanya mengkonfigurasi dengan menekan tombol sekali. Satu batch diisikan sebanyak 200 kartu dan dilengkapi motor aktuator dan beberapa sensor untuk mendeteksi posisi kartu yang sudah terpasang di slot.

\section{Perbaikan Storage System}

Pada kondisi saat ini, slider-block yang diikat oleh beban sebagai penggerak dilakukan perbaikan dengan menerapkan sistem otomasi pada motor DC untuk gerakan maju dan mundur. Kemudian setelah proses punching selesai, pekerja tidak peril menarik kabel katrol yang dikaitkan, mendorong tuas penjepit, dan melepas kartu jadi. Setelah proses selesai, kartu tersebut turun ke dalam tempat penyimpanan di bawah mesin punching secara otomatis.

\section{B. Analisis Konfigurasi PLC}

PLC CP1E dengan spesifikasi CPU N30 memiliki 18 modul input terdiri dari alamat 100.00 - 100.11 dan 101.00 - 101.05, sedangkan untuk modul output terdiri dari 12 dimulai dari alamat $0.00-0.08$ dan $1.00-1.03$. Dari keseluruhajhduf jdhfu $\mathrm{n}$ alamat input dan output yang telah diprogram dan diinstalasi terbukti telah berhasil dilakukan uji coba simulasi. Simulasi Semua sensor dan aktuator berjalan sesuai dengan program yang diinginkan. Untuk kapasitas memori pada PLC Omron CP1E sebesar 8K dan spesifikasi dapat dilihat pada Gambar 9.

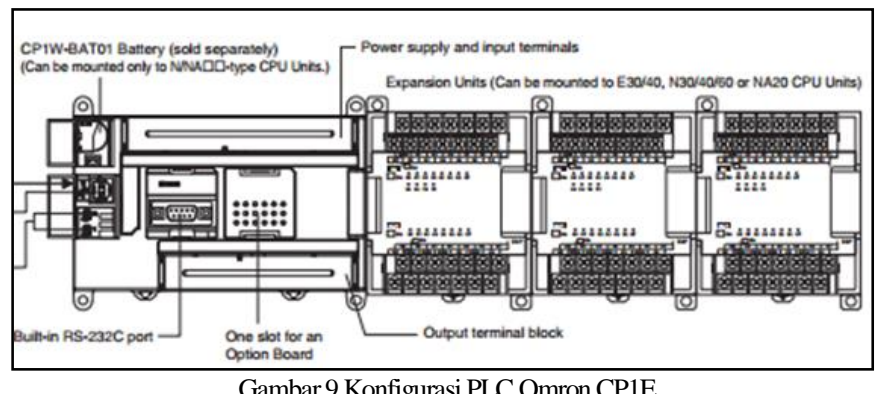

Berdasarkan Gambar 9, untuk melakukan konfigurasi pada PLC Omron CP1E dengan komputer yang kemudian dikoneksikan menggunakan protokol komunikasi RS-232C.

\section{Analisis Program PLC}

Penelitian ini memiliki dua program yang berbeda yaitu program untuk melakukan proses pelubangan kartu jacquard dan program untuk menjalankan mekanisme otomatis mesin punching. Berdasarkan Tabel V dijelaskan gambaran deskripsi setiap program yang telah dibuat.

TABEL V

DESKRIPSIPROGRAM PLC

\begin{tabular}{|c|c|l|}
\hline No. & Nama Program & \multicolumn{1}{|c|}{ Analisis Program PLC } \\
\hline 1. & $\begin{array}{c}\text { Program } \\
\text { Pelubangan Kartu } \\
\text { Jacquard }\end{array}$ & $\begin{array}{l}\text { Program PLC ini dirancang untuk } \\
\text { merepresentasikan program utama pada } \\
\text { proses pelubangan kartu jacquard dan } \\
\text { mengolah hasil biner yang mengaktifkan } \\
\text { seluruh isi program punching. }\end{array}$ \\
\hline 2. & $\begin{array}{c}\text { Program } \\
\text { Mekanisme Mesin } \\
\text { Punching }\end{array}$ & $\begin{array}{l}\text { Program PLC ini dirancang untuk } \\
\text { menjalankan mekanisme mesin secara } \\
\text { otomatis untuk menggantikan peran } \\
\text { operator dan meminimasi beban kerja. }\end{array}$ \\
\hline
\end{tabular}

Program PLC yang dibuat perlu dipahami oleh operator untuk dapat dijalankan secara benar. Program yang tepat adalah program yang 
dirancang dengan memiliki sistem closed-loop atau memberikan umpan balik apakah terdapat program yang sesuai maupun terjadi kesalahan program. Hal ini perlu diinformasikan kepada operator atau user untuk dapat dilakukan proses pemeriksaan atau troubleshooting. Untuk itu didesain salah satu tool dari alur proses diagram yang menjelaskan tentang alur proses program PLC yaitu Sequential Functional Chart (SFC) yang dijelaskan pada Gambar 10.

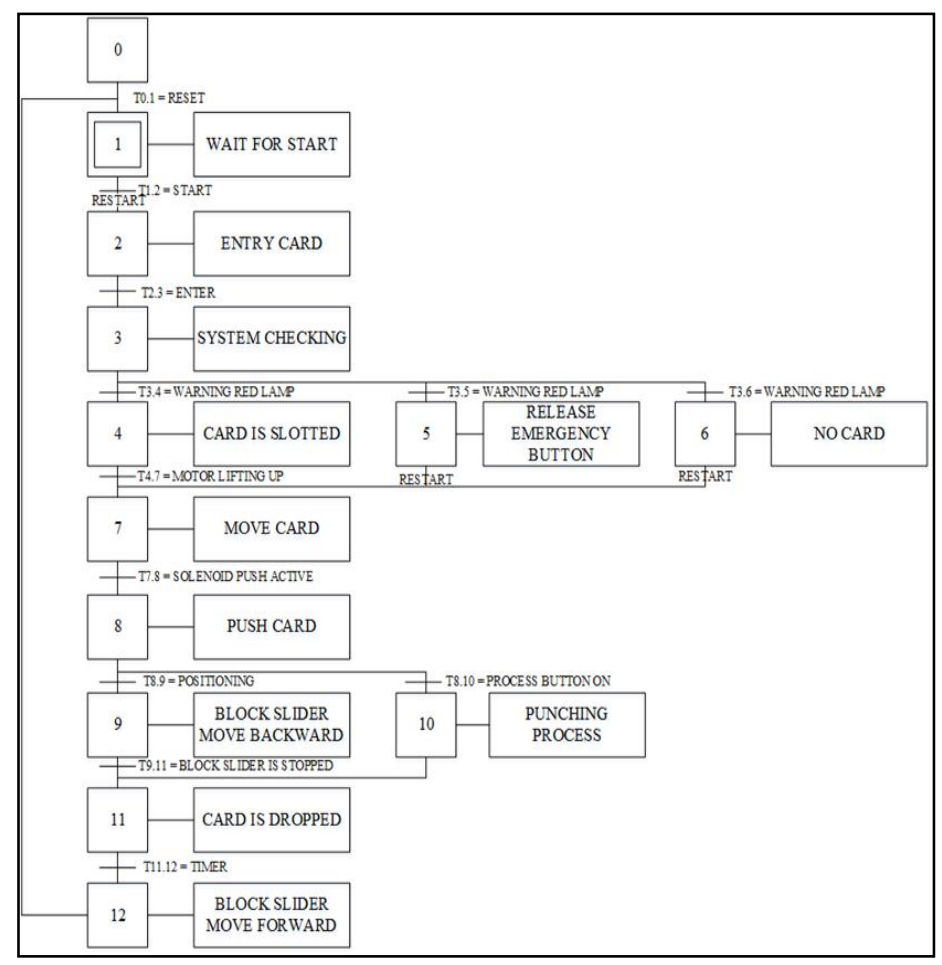

Gambar 10 Diagram hasil SFC

Diagram pada Gambar 10 dijelaskan terdapat 12 steps yang saling berhubungan satu sama lain dimana menggambarkan proses closedloop. Steps merupakan perpindahan aktivitas pada sebuah sistem. Dimulai dari proses awal yaitu memasukkan bahan mentah kartu jacquard yang kemudian diproses hingga kartu yang telah selesai di punching.

\section{Analisis Uji Simulai Sistem PLC}

Simulasi Uji simulasi merupakan tahap akhir pada penelitian ini. Dilakukan untuk memastikan sistem yang dirancangan dan diimplementasikan pada model desain baru untuk mengetahui terjadinya failure system dan error.

Dapat ditinjau dari hasil uji bahwa perancangan sistem autofeeder dan sistem storage dapat mengurangi waktu siklus pada kondisi saat ini. Pekerja tidak perlu melakukan aktivitas berulang seperti pengambilan kartu dan meningkatkan waktu siklus menjadi konsisten. Uji simulasi dilakukan dengan dua kondisi yaitu simulasi langsung pada model mesin modifikasi dan simulasi pada perangkat lunak. Dengan membandingkan kedua hasil uji ini terlihat memiliki perbedaan yang tidak cukup jauh yaitu hanya memiliki perbedaan waktu sebesar 0.5 detik. Setelah dilakukan simulasi dengan menggunakan software Computer Aided Design (CAD) dan simulasi software monitoring HMI didapatkan hasil sebagai berikut yang dijelaskan pada Tabel VI. Untuk memastikan sistem berjalan dengan kondisi yang diharapkan.

TABEL VI

HASIL ANALISIS SISTEM PERBANDINGAN

\begin{tabular}{|c|c|c|c|}
\hline No. & Kategori & Kondisi Saat Ini & Kondisi Usulan \\
\hline 1. & $\begin{array}{c}\text { Proses } \\
\text { Transferring } \\
\text { Card }\end{array}$ & $\begin{array}{l}\text { Dilakukan secara } \\
\text { manual oleh } \\
\text { operator dengan } \\
\text { waktu rata-rata } 6 \\
\text { detik/kartu }\end{array}$ & $\begin{array}{l}\text { Dengan menggunakan } \\
\text { autofeeder, sehingga } \\
\text { tidak membutuhkan } \\
\text { operator dengan rata- } \\
\text { rata waktu } 3 \text { detik/kartu. }\end{array}$ \\
\hline 2. & $\begin{array}{l}\text { Mekanisme } \\
\text { Block Slider }\end{array}$ & $\begin{array}{l}\text { Dilakukan secara } \\
\text { manual dengan } \\
\text { menarik bandul } \\
\text { dengan rata-rata } \\
\text { waktu } 7 \text { detik/kartu }\end{array}$ & $\begin{array}{l}\text { Dengan menggunakan } \\
\text { sistem motor otomasi, } \\
\text { tidak membutuhkan } \\
\text { operator dengan waktu } \\
\text { rata-rata } 3 \text { detik/kartu. }\end{array}$ \\
\hline 3. & $\begin{array}{c}\text { Kebutuhan } \\
\text { Pekerja }\end{array}$ & $\begin{array}{l}\text { Dibutuhkan satu } \\
\text { operator untuk } \\
\text { melakukan aktivitas } \\
\text { produksi dan } \\
\text { melakukan } \\
\text { pengawasan setiap } \\
\text { waktu. }\end{array}$ & $\begin{array}{l}\text { Tidak dibutuhkan } \\
\text { operator khusus untuk } \\
\text { melakukan setup mesin } \\
\text { dan tidak melakukan } \\
\text { pengawasan setiap } \\
\text { waktu. }\end{array}$ \\
\hline
\end{tabular}

Berdasarkan hasil analisis dan uji simulasi sistem yang telah didesain dan diimplementasi, didapatkan bahwa sistem otomasi yang diprogram dengan program PLC pada mesin punching kartu jacquard terbukti berhasil sesuai dengan alur proses kemudian dapat meminimasi beban aktivitas pekerja yang berulang-ulang. Desain model dan sistem program PLC menggunakan Omron $\mathrm{CP} 1 \mathrm{E}$ dan perangkat lunak $C X$ Programmer Ver. 9.4 telah berhasil mengontrol mesin sesuai skenario. Waktu siklus produksi kartu jacquard yang telah diimplementasi oleh sistem otomasi dapat berkurang hingga 10 detik per kartu. Dengan ini dapat memenuhi kapasitas target produksi sebanyak $300 \mathrm{kartu} / \mathrm{hari}$.

\section{DAFTAR PUSTAKA}

[1] M. Moelino, "Pengembangan Ragam Desain Struktur Pada Kain Sandang Tradisional Dengan Menggunakan Mesin Tenun Jacquard Elektronik," Arena Tekstil, vol. 30 , no. 1, pp. 13-24, 1 Juni 2015.

[2] J. Delve, "Joseph Marie Jacquard: Inventor of the Jacquard Loom," IEEE Annals of the History of Computing, vol. 29, pp. 98-102, December 2007.

[3] P. B. "Data Permintaan Corak Kain Sajadah," 2016.

[4] M. P. Groover, Automation, Production Systems, and Computer-Integrated Manufacturing, Third Edition ed., New Jersey: Pearson Education Inc., 2008.

[5] P. Chlique and H. Guegen, "User's Requirement Specification for Control : an Object-Oriented Approach," Proceedings Computers in Design, Manufacturing, and Production, pp. 296 - 301, 2002. 
[6] M. I. Fauzan, Automation System Design For Stopper Valve Chamfering Process On Bench Lathe SD-32A Machine At PT. Dharma Precision Parts, Bandung: Telkom University, 2015.

[7] L. J, Process Automation Handbook, London, 2007.

[8] F. Ebel and S. Idler, Fundamentals of Automation Technology, R. Pittschellis, Ed., Denkendorf: Festo Didactic GmbH, 2008.

[9] F. D. Petruzella, Industrial Electronics, New York: McGraw-Hill, 1996. 